\title{
Curriculum as a Resource for the Development of Social Identity
}

Stanton Wortham

University of Pennsylvania, stanton.wortham@bc.edu

Follow this and additional works at: https://repository.upenn.edu/gse_pubs

Part of the Education Commons

\section{Recommended Citation}

Wortham, S. (2003). Curriculum as a Resource for the Development of Social Identity. Retrieved from https://repository.upenn.edu/gse_pubs/210

Suggested Citation:

Wortham, S.E.F. (2003). "Curriculum as a Resource for the Development of Social Identity." Sociology of Education. Vol. 76. p. 229-247.

(C) 2003 American Sociological Association http://www.asanet.org/journals/soe/index.cfm

This paper is posted at ScholarlyCommons. https://repository.upenn.edu/gse_pubs/210

For more information, please contact repository@pobox.upenn.edu. 


\title{
Curriculum as a Resource for the Development of Social Identity
}

\author{
Abstract \\ This article describes how categories from the curriculum can play a central role in the interactional \\ construction of students' identities. Drawing on data from one ninth-grade English and history class \\ across an academic year, the article describes an adolescent who was assigned and came to enact the \\ identity of a disruptive outcast from the classroom community. It then describes how this student's \\ identity development was facilitated by discussions of a curricular theme. The article traces the student's \\ trajectory across the year and then analyzes one classroom discussion in detail, showing the interactional \\ construction of her alienation from school and how this construction was mediated through curricular \\ categories. \\ Disciplines \\ Education \\ Comments \\ Suggested Citation: \\ Wortham, S.E.F. (2003). "Curriculum as a Resource for the Development of Social Identity." Sociology of \\ Education. Vol. 76. p. 229-247. \\ (C) 2003 American Sociological Association \\ http://www.asanet.org/journals/soe/index.cfm
}




\title{
Curriculum as a Resource for the Development of Social Identity
}

\author{
Stanton Wortham \\ University of Pennsylvania
}

This article describes how categories from the curriculum can play a central role in the interactional construction of students' identities. Drawing on data from one ninth-grade English and history class across an academic year, the article describes an adolescent who was assigned and came to enact the identity of a disruptive outcast from the classroom community. It then describes how this student's identity development was facilitated by discussions of a curricular theme. The article traces the student's trajectory across the year and then analyzes one classroom discussion in detail, showing the interactional construction of her alienation from school and how this construction was mediated through curricular categories. 
As the students and teachers in Mrs. Bailey and Mr. Smith's ninth-grade English and history class worked with each other--usually five days a week, 80 minutes a day, from September to June--they consistently participated in at least two types of processes. One involved their developing relationships and social identities. On the first day, they could tell that 5 students were boys and 14 were girls; that 15 students were black, 3 were white, and 1 was Asian; and that both teachers were white. But they did not yet know whether the students would behave in ways that were stereotypically expected for their gender and ethnicity. Nor did they know which students would be "cooperative" and which "disruptive"; which would be "clowns" and which "resistant"; or whether the teachers would be "easy" or "strict," "pushovers" or “disciplinarians." Within a couple of months, however, everyone had a presupposable classroom identity. Some of these identities were hybrid or unstable, and some changed during the year. But at any point, there was a substantial consensus about who various people were.

The second type of process that was going on in the classroom involved learning the curriculum. At the same time as the students and teachers were getting socially identified, they were also discussing the curriculum. Over the year, the students learned many facts and learned to make arguments about broad curricular themes. For instance, they learned to make arguments about how society should be organized--specifically, about whether individuals should subordinate their desires for the good of the group or whether the society should maximize individual satisfaction. This learning took place, in large part, through the same classroom discussions that established the social identities of both the teachers and the students.

I argue that these two classroom activities--the development of social identity and learning the curriculum--sometimes mediated each other. Particular students developed identities, in part, because discussions of certain curricular themes provided categories that the 
teachers and students used to identify them. Curricular themes facilitated identity development because they described particular types of people and the social roles that such people typically adopt. The students and teachers did more than learn these categories of identity as the content of the curriculum. They also used such categories to organize their relationships with particular students. Thus, the interactional construction of students' identities depended, in part, on categories that were drawn from the curriculum. This article describes in detail how this interdependence between social identification and the curriculum occurred, analyzing how one student's emerging social identity depended on curricular categories.

\section{SOCIAL IDENTIFICATION}

To show how curricular categories can contribute to students' identity development, I first need to sketch an account of social identification. Recent conceptualizations of social identity have struggled to describe how individual identities emerge from, but are not simply derived from, social categories and practices (e.g., Holland and Lave 2000). This article shows how particular social identities emerge from but also transform presupposed sociocultural patterns and how this process can be mediated through the academic curriculum.

\section{Timescales}

Processes at several timescales are relevant to understanding students' developing identities (Cole 1996; Lemke 2000). First, as Bakhtin (1935/1981) showed, individuals do not own words or categories. We "rent" them from society. Categories of identity exist at a "sociohistorical" timescale, persisting and changing over decades and centuries. Second, particular students develop identities over "ontogenetic" time (months and years), drawing on but also developing 
sometimes-unique configurations of sociohistorically circulating categories. Third, sociohistorical and ontogenetic categories of identity are used and inflected in mesolevel contexts, over weeks, months, and years. As Plank (2000) and others have shown, for instance, individual classrooms develop distinctive activities, structures, and styles, and these distinctive features can influence classroom relations and students' identities. This article describes how more widely circulating categories of identity were construed in particular ways in one classroom over a year and how these mesolevel categories were used to identify one student. Fourth, there are "microgenetic" patterns, analyzed from what Goffman (1974) called the “situational" perspective. Sociohistorical, ontogenetic, and mesolevel regularities exist empirically only in particular events--like classroom conversations among teachers and students--as participants in classroom interactions enact recognizable types of events and adopt socially recognizable positions over seconds, minutes, and hours.

An account of social identification in the classroom must explain how mesolevel and ontogenetic categories of identity are drawn from the sociohistorical context into a classroom over an academic year, such that specific versions of the categories come to frame students as having recognizable identities. The invocation of sociohistorical and mesolevel categories of identity and the ontogenetic social identification of an individual happen only in particular (microgenetic) events as certain categories come repeatedly to frame events involving the focal individual.

\section{Constructing Identity}

Theories of social identification describe various relationships between sociohistorical, mesolevel and microlevel timescales. Some emphasize the power that "structural" and "cultural" 
sociohistorical factors have to impose identities on individuals, while others emphasize the construction of unexpected identities in particular contexts. But the stark opposition between determinists (e.g, Bowles and Gintis 1976) and constructionists (e.g., Gergen 1991) has given way to more nuanced processual accounts. Most now agree that sociohistorical categories must be presupposed for social identification to occur at the microlevel and that structural patterns are often reproduced in particular contexts. But most also agree that mediating factors at the mesoand microlevels play an essential role in the production and reproduction of sociohistorical categories and that unique, sometimes divergent, patterns can be constructed in particular contexts.

Lareau (2000; see also Lareau and Horvat 1999), for instance, described how race and class positions influence success in school only as parents differentially position themselves with respect to school. Although she emphasized the importance of social class, her studies have shown how structural constraints and resources are used variably and received variably in mesoand microlevel contexts. O’Connor (2001), in her account of how structurally similar families construe their racial identities and opportunities for advancement differently, emphasized the flexibility of identity construction more than did Lareau. But she gave a similar account of how structural and cultural constraints and resources play an important role, taking different forms as they get mediated through meso- and microlevel contexts. Lee (1996), too, emphasized the variability of particular groups' responses to structural constraints and widely circulating stereotypes, showing how the process of social identification involves both sociohistorical and more local components.

All these contemporary accounts of social identification have included patterns from several different timescales. Sociohistorical structures, practices, and ideas play an essential role, 
but only as they are mediated through particular meso- and microlevel contexts. Identities are often predictable from larger patterns, but even in such cases we must describe the meso- and microlevel mediations through which they get produced. Furthermore, in cases like the one described in this article, important aspects of an individual's emerging identity are sometimes not predictable from larger patterns.

\section{Signs and Metasigns of Identity}

To analyze this multilevel process of social identification, we must distinguish between signs that identify the person as a member of a certain social type and circulating "metasigns" that identify enactable social types (Agha forthcoming; Bourdieu 1984; Sacks 1972; Silverstein and Urban 1996; Wortham 2001b). Goffman (1963), for instance, distinguished between a person's physical deformity and the normative expectations that make it a "stigma." To a native, signs of identity (e.g., a physical deformity, distinctive clothing, or the use of a particular speech register) appear to be accomplishing social identification by themselves. But they do so only by presupposing broader social categories. These presuppositions circulate through social space and allow hearers or observers to construe particular uses of a sign. They thus constitute a "metasign of identity"--a set of beliefs that can frame particular features or behaviors as having been about a recognizable social type.

Bourdieu (e.g., 1984) described circulating social metasigns in terms of a symbolic "market." People recognize particular signs because they participate in a symbolic marketplace that values various forms of speech, styles of dress, and taste in art differentially. Although Bourdieu was clearly correct that we use metasigns or social standards of value in everyday judgments about identity, his market metaphor does not work well for some aspects of social 
identification. A market metaphor suggests one standard and that people are fundamentally interested in "buying" symbolic status and economic advantage. But it seems more plausible that various possible metasigns or standards of value may be circulating in any social context. When a participant says or does something, others must often decide which of several presupposable identities he or she is enacting there--that is, which circulating metasigns are framing that utterance or behavior.

From this perspective, a particular individual's development of a social identity occurs when certain metasigns of identity come to circulate more regularly through events involving this individual (Agha forthcoming; Wortham 2001b). To become an outcast, for instance, presupposes a social group that coheres along some social dimension and an individual whom the group identifies as violating the group's principle of cohesion. The analysis presented here illustrates how a specific version of this metasign of identity came increasingly to organize interactions that included one student in Mrs. Bailey and Mr. Smith's classroom. Before I present the analysis, however, it is necessary to describe the role that curriculum can play in providing metasigns of identity.

\section{Curricular Metasigns of Identity}

This article shows how the curriculum can be a source for metasigns of identity. In the classroom described here, the curriculum centered on certain questions of enduring human concern. The texts the students read--a remarkable set of classic texts from diverse cultural traditions, including the Upanishads, Aristotle, Cicero, Shakespeare, Hammurabi's Code, and creation myths from around the world--engage with basic questions that all humans face. For instance, all societies face the question of whether individuals should sacrifice their desires for the good of 
the group, or whether a society should be organized so as to allow maximal individual freedom. The teachers assigned texts from many cultural traditions that took different positions on this issue (e.g., Plutarch's "Life of Lycurgus," which describes the collectivist ancient Spartan system, as opposed to Ayn Rand's Anthem, which advocates extreme individualism). They wanted the students to recognize this issue when they saw it, to know that reasonable people can differ in their views, and to produce arguments for their own positions on the issue.

Like any curriculum, this one drew on sociohistorical patterns that persist over centuries and decades. Intellectual positions about collectivism and individualism have developed historically in various traditions, and the curriculum in this classroom drew on exemplars from various times and places. Particular arguments about individual freedom or some other issue make sense only against the background of these historically developing ideas. Furthermore, these historical ideas about collectivism and individualism presuppose metasigns that identify characteristic types of people. From a collectivist perspective, for instance, there are comrades who contribute to the collective good and freeloaders who undermine it. Categories like this can be mobilized to identify particular teachers and students, especially when issues from the curriculum are illustrated with examples that draw on the students' own experiences. The analysis presented here shows how, for one curricular theme, a particular student became the preferred example. As the students and teachers discussed this student as an example of the theme, the students learned about the curriculum, and the student in question developed a particular identity.

The social identities of particular students and the discussion of certain curricular themes came together through a pedagogical strategy--one certainly not unique to these teachers--in which they drew analogies between students' experiences and the curriculum. Classroom 
experience itself offers many potential grounds for analogy. For instance, a classroom "society" must determine how collectivist or individualist it will be. Will individuals always be asked to subordinate their interests and desires for the good of the whole, or will they often get to pursue what they want? Different teachers organize their classrooms differently, and the actual relationships that develop in diverse classrooms enact different answers to this question. When teachers and students use their own experiences as members of a classroom "society," as an analogy to curricular issues about collectivism and individualism, students can both learn about the curriculum and develop identities simultaneously. The analysis presented here shows how Tyisha, a student in Mr. Smith and Mrs. Bailey's class, became an example of an outcast from the classroom "society" and was identified as disruptive.

The analysis traces how Tyisha developed an aspect of her identity, in one classroom, over an academic year. What happened in this classroom represents only one aspect of this student's ontogeny, of course. Tyisha may have enacted different identities in other aspects of her life, while she was becoming an outcast in this classroom, and she may have become someone different after this school year ended--I do not have data on these questions. But the analysis shows that she started out being treated as one kind of person in this classroom and that she developed into someone quite different over the year. This change in her social identity drew on sociohistorical metasigns about types of people, as these metasigns were taken from the curriculum and inflected in this particular classroom. And it was accomplished through repeated microgenetic enactments in particular classroom conversations. The analysis gives a representative example of how this identity development occurred and illustrates how Tyisha's mesolevel identity was constructed using categories from the curriculum. 


\section{METHODS AND ETHNOGRAPHIC BACKGROUND}

Colleoni High is a large three-story brick building that occupies an entire city block. When it was built about 50 years ago, Colleoni enrolled primarily Catholic children from Irish and Italian backgrounds. The neighborhood has since become predominantly black, together with growing populations of Latino and South Asian immigrants. In the early 1990s, when I was there, the student body was ethnically mixed and mostly working and lower class. Fifty percent of the students were black, 25 percent were Latino, 15 percent were white, and 10 percent were Asian. The faculty contained many whites, some blacks, and a few Hispanics.

I spent a total of 128 hours at Colleoni over two years, more than 100 of them in classes. Three quarters of those classroom hours came in the final year, when I audiotaped most classes that I observed. Throughout my time at Colleoni, I took fieldnotes. I also had many informal conversations with teachers after classes and scheduled interviews with teachers, administrators, and students. I spent about 50 hours in one particular class throughout the final year. As I mentioned earlier, 15 of the 19 students in this particular ninth-grade class were black and 14 were female.

Like many other schools in the city, Colleoni participated voluntarily in desegregation by offering a special educational program to students from throughout the district. At Colleoni, the program was based on guidelines from The Paideia Proposal (Adler 1982). Parents and educators considered this program to be academically superior to the programs in most neighborhood schools, but not as good as the prestigious magnet programs. About one quarter of the students at Colleoni participated in this special program. Most of these students did not live in the neighborhood, and some commuted well over an hour each way.

Adler (1982) recommended that students discuss "genuine questions." That is, "seminar" 
discussions should involve students presenting and defending positions on complex questions, not simply parroting the teacher's preferred answers. The two ninth-grade teachers I observed in the final year, Mrs. Bailey and Mr. Smith, ran joint history/English classes twice a week, when they had 80-minute seminar discussions with the 19 students. The other three days a week, each teacher conducted more conventional didactic lessons for 40 minutes each. Increasingly over the year, the teachers engaged the students in rich discussions of complex texts--discussions in which the students came to recognize issues of enduring human concern and to formulate their own arguments about these issues.

I made contact with Colleoni through the administrator who ran the special program. I told him I was interested in observing the program itself, as well as the use of language in the classroom. The administrator selected certain teachers for me to talk to. I spoke with these teachers, received permission from them, and then began to visit their classrooms. I introduced myself to the teachers as someone who had read a lot about classrooms in books, but who did not know much about them in practice. I tried to minimize any authority I brought with me from the university by presenting myself as a novice who wanted to learn how teaching and learning actually happen. Nonetheless, the teachers were initially uncomfortable with me in their classrooms. I received many sidelong glances, as well as indirect requests for information on what I was doing and what I thought of them as teachers.

I was introduced to the students as an observer who was interested in the teaching methods in Colleoni's special academic program. These students were used to observers--I saw a steady flow of visitors, including administrators, student teachers, and others who were interested in the special academic program. Nonetheless, like the teachers, at first the students wondered who I was. After a few weeks, however, the teachers and students most often took me 
for granted during class. They clearly knew I was there, especially when I began recording. After a particularly bad joke, someone would occasionally comment "and that was recorded for posterity." But after the first few weeks of recording, I noticed few differences between the classes I had observed without recording equipment and those I audiotaped.

As I mentioned earlier, the analyses for this article focused on examples in which students' own experiences were presented as analogous to concepts from the curriculum. In analyzing the tapes and fieldnotes from Mr. Smith and Mrs. Bailey's class, I focused on such examples. I transcribed all examples that included such analogies and analyzed them for any implications they might have for students' social identities. The methods of discourse analysis, which identify types of cues that often serve as signs of identity, are described in Wortham (2001b). In addition, I went through all the tapes and notes, looking for explicit statements about and implicit positioning relevant to Tyisha's identity in particular. The data analyses in the next section present representative instances from throughout the year in which Tyisha got socially identified, plus one extended example that illustrates how categories from the curriculum were used to identify her.

\section{TYISHA, THE OUTCAST}

From near the beginning of the year in Mrs. Bailey and Mr. Smith's class, the teachers and most students presupposed that girls and boys have different social identities with respect to school. As Mrs. Bailey said explicitly one day, girls are easier for teachers to deal with because they conform to school expectations and thus are more likely to succeed in school and in adulthood. Boys are more difficult to deal with because they resist school expectations and are less likely to succeed both in school and in later life. This expectation about identity draws on circulating 
sociohistorical patterns, like those that identify black male students as particularly concerned with respect and more likely to resist participation in school (Anderson 1999; Ferguson 2000). But the gender difference was especially salient in this classroom for two reasons. First, Mrs. Bailey believed what she said--she both explicitly and implicitly stated it throughout the year, and the girls took many opportunities to remind the boys about these presupposed gender differences. Second, from early in the year, the boys all tried to sit together in the back of the room, and all but one of them generally refused to participate, while many girls participated actively and dominated the classroom discussions.

\section{From Normative Girl to Outcast}

At the beginning of the year, Tyisha fit this gender stereotype: She was an active, successful female student. She was engaged, offering her opinions on many subjects related to the class discussions. Most of the students started the year trying to figure out and parrot back what the teachers wanted them to say. Because Tyisha rarely did so, but instead offered her own opinions, the teachers initially identified her as a student who made her own arguments. In a Paideia seminar, such independence of thought is desirable, so Tyisha was treated as a normal, even a good student.

The following segment comes from a class on October 9. (“Mrs. B” stands for Mrs. Bailey; "Female" stands for an unidentified female student; transcription conventions are presented in the appendix).

1 Mrs. B: OK, we've got women having ba:bies. how does that

$2 \quad$ relate to having women goddesses?

3 Tyisha: It $\underline{\text { doesn't, to me. }}$ 
$4 \quad$ Mrs. B: It doesn't to you. How about you?

$5 \quad$ Female: Maybe they think that that's supernatural.

6 Mrs. B: That that's supernatural? Having a baby is supernatural.

At line 3, Tyisha failed to give an answer the teacher was looking for. She also emphasized her opinion by adding the phrase "to me." But Mrs. Bailey did not evaluate Tyisha negatively. In fact, she repeated Tyisha's utterance with similar stress and went on to ask for another student's opinion, with a parallel stress on "you." Mrs. Bailey often asked several students in turn for their opinions on issues raised in the text, and here we see how Tyisha's habitual personalization of her opinions fit the teacher's expectations. Especially early in the year, the teacher reacted positively to Tyisha's offering her own opinions because she wanted other students to do the same.

Later on in the October 9 class, Tyisha said something deliberately off-topic, apparently as a joke. In the following segment, they were discussing bees to understand a Chinese myth that compares humans to insects:

$1 \quad$ Mrs. B: Bees do what?

2 Tyisha: Kill.

3 Students: [laughter]

4 Maurice: Some bee pollen, they raise [pollen

5 Mrs. B: [they fertilize=

$6 \quad$ Female: Flowers.

7 Mrs. B: What do spiders do? They fertilize plants. Bees are

8 people who, are insects who ahh, Cassandra?

At line 3, several students treated Tyisha's comment as a joke through their laughter. It was a 
small joke, but successful. Note that the teachers did not discipline Tyisha for this comment. Mrs. Bailey simply ignored Tyisha's comment and continued with the discussion. Tyisha then reentered the conversation more constructively.

$1 \quad$ Mrs. B: How long do insects live?

2 Candace: Maybe 10 days, about [a week

3 Maurice: [a week.

4 Mrs. B: A day, a couple of months, alright.

$5 \quad$ Tyisha: Some of them a day because you know, if they bite

6 you, they die.

7 Mrs. B: OK some of them as soon- as soon as they, they, they

8 put their stinger in it, they're dead. $\underline{\mathrm{K}}$, now put that back

9 to Pampu. Why might the $\underline{\text { Chinese believe or feel that ma:n }}$

10 comes from the earth as an insect. That ma:n is similar to

11 an insect?

At lines 7-8, Mrs. Bailey restated and thus ratified Tyisha's comment as a useful contribution, one that allowed Mrs. Bailey to go on to her analogy between the mortality of bees and the idea of humans as insects (at lines 8-11).

At the beginning of the year, then, the teachers treated Tyisha as a normal student. They appreciated her opinions and did not discipline her when she made jokes. After a month or two, however, several other students learned to offer arguments and give evidence as the teachers wanted. At this point, the teachers increasingly distinguished between Tyisha's comments--which they began to characterize as "opinions" offered without supporting evidence--and those from more successful students who gave better arguments. Tyisha's 
behavior had not changed much. But relative to the teachers' expectations and to other students' increasingly successful participation, it looked as if Tyisha was acting differently. In December and January, both the teachers and the other students began to identify Tyisha as a disruptive student instead of a good one.

Evidence for this changed view of Tyisha comes from the teachers' increasingly blunt evaluations of her. Right before the following segment (from January 18), Mrs. Bailey had given an interpretation of Aristotle's text. She noted that Aristotle does not say that women are slaves to men, only that the relationship between a man and woman is partly analogous to the relationship between a master and a slave.

1 Tyisha: OK, when- um Sylvia was talking about the slave

2 and the ma:ster, the master, OK, the slave, he uses

3 his hands and stuff but- they won't give him a chance to use

4 his- to teach him to read and stuff and the master know

5 how, so he using his mind. why does he [4 unintelligible

$6 \quad$ syllables]

7 Mrs. B: $\quad$ [OK, didn't- you

8 just missed the connection, the con- the thing is that-

9 do not look at this as saying that $\underline{\text { slaves }}$ are manual workers,

10 slaves- women are slaves. look at these as four distinct

11 relationships.

Tyisha's reasoning may have wandered a bit from lines 1 to 6 , but Tyisha was apparently struggling with issues relevant to the text. Nonetheless, Mrs. Bailey interrupted to tell her, "You just missed the connection" (lines 7-8). 
This incident alone may have been momentary impatience on the teacher's part, but the following evaluation followed immediately:

16 Mrs. B: And in Greeks- in Greece, there certainly were

17 slaves that used their mind. Yeah?

18 Female: I'm talking about going back to what Tyisha said

19 about how slaves that- well- if, OK if a master didn't teach

20 the slaves how to read, how did they learn how to read?

21 How did we know how to read and talk ourselves?

22 Mrs. B: o[K, you just missed-

23 Tyisha: [right, thank you.

24 Mrs. B: You just missed the point.

25 Jasmine: You missed the point. We're not compari[ng them.

26 Tyisha: [I know,

27 but I'm talking about-

28 Mrs. B: OK, look at this again, mental, manual workers,

29 are mental workers

At line 18, a student referred back to the earlier comment by Tyisha, building on Tyisha's comment to ask a question. Normally, these teachers encouraged the students to refer to each other's comments as a way of developing more complex arguments across the group. And at line 23, Tyisha explicitly thanked the other student for resuscitating her point and asking the question.

But Mrs. Bailey immediately jumped in (at line 22) and returned to her earlier evaluation of Tyisha's point, with similar phrasing: "You just missed the point." The speed of Mrs. Bailey’s 
intervention and her blunt characterization of Tyisha's (and the second student's) point was uncharacteristic of this class. These teachers wanted the students to develop their own arguments, and they generally helped students who were struggling to articulate something. But by January, they had started to presuppose that Tyisha's points would not contribute to the conversation--that her comments were disruptive and not substantive. Note that another student (Jasmine) echoed Mrs. Bailey's evaluation of Tyisha, at line 25. Other students, too, had come to presuppose that Tyisha was disruptive. Jasmine also used "we" in line 25, probably to distinguish Tyisha and her one defender from the teachers and the other students.

This split between Tyisha and the rest of the girls broadened over time as Tyisha was increasingly identified as a disruptive student. The teachers continued to react quickly and harshly to many of her comments, presupposing that her contributions were intellectually unproductive and disruptive. The following segment, for instance, is from a discussion on January 25.

$1 \quad$ Mrs. B: OK. Well, I think that he's talking more not

2 about not being with people, but that he: will $\underline{\text { not }}$

3 have to have people bail him out at any point. He

4 can make it on his own.

5 Tyisha: So you gonna be the only person living

6 there?

7 Mrs. B: №. That's not what he's saying, Tyisha.

8 Candace: He's saying that he can live without people

9 helping him.

At lines 1-4, Mrs. Bailey summarized her interpretation of a point. Tyisha offered a gloss at lines 
5-6, a gloss that misstated Mrs. Bailey's point, and the teacher reacted immediately by telling Tyisha that she was wrong. This quick and blunt response contrasts with the teachers' habitual reaction to other students and to Tyisha earlier in the year, when the teachers would have explored her point or been gentler in evaluating her response. Another student gave a more accurate gloss at lines $8-9$, and the class continued to discuss the point, ignoring Tyisha.

By February, Tyisha's identity as a disruptive outcast had solidified. It was then generally presupposable that she was disorganized, prone to offer comments that took the class off-topic, and concerned with her own ideas more than with helping the group develop a coherent discussion. Thus, Tyisha became an exception to the gender stereotype that teachers and students continued to presuppose. She was a girl who nonetheless was not a good student and was not likely to succeed.

As Tyisha's identity as a disruptive outcast got increasingly presupposed, she was characterized as disruptive even when she was absent. In the following segment, from February 7, Brenna summarized the Spartan practice of infanticide:

1 Brenna: They just put them out an- as a test. If it lives

2 then it's strong. And if it dies then it dies.

3 Mrs. B: I'm going to play Tyisha. That's not right

4 Students: hahahahaha

$5 \quad$ Mrs. B: These people are stupid. That's not right

$6 \quad$ we're $[=$

7 Students: $\quad[$ hnh haha

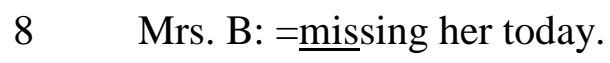

9 Students: [7 seconds of comments and laughter] 
10 Mrs. B: She- you know that's what she'd say? What

11 is your response to that?

12 Students: [unintelligible response] hahahahaha

13 Mrs. B: You'd never say that when she's in the room.

When Mrs. Bailey “played” Tyisha at lines 3-5, she identified Tyisha as opinionated and judgmental. She also presupposed that the other students were cowed by Tyisha (at line 13).

By early February, Mr. Smith was characterizing Tyisha explicitly as a bad student who did not listen. The following segment is from the class on February 11:

1 Mr. S: I will do a spot check, spot check your notebook.

2 the notebook, and you better listen Tyisha, because you

3 have a habit of never listening to $\underline{\text { me. }}{ }^{\circ}$ Tyisha $^{\circ}$

4 Tyisha: I know what you're talking about[

5 Mr. S:

$[$ no.

6 Tyisha: You're talking about [the notebook

7 Mr. S:

$\left[{ }^{\circ}\right.$ your ears are unfortunately

$8 \quad$ closed sometimes. ${ }^{\circ}$

15 Mr. S: Number five. Who made the laws?

16 Female: The assembly.

17 Mr. S: OK [ what page?

18 Tyisha: $\quad\left[{ }^{\circ}\right.$ the $\mathrm{king}^{\circ}$

19 Mr. S: No, you're wrong. Because you're guessing without

20 looking. And that is $=[$ 
21 Tyisha: [no way.

22 Mr. S: =exactly what you do as a bad[ student.

23 Tyisha: [no I wasn't

24 Mr. S: Halt.

At line 3, Mr. Smith said that Tyisha never listened to him. And at line 22, he called her a bad student. Mr. Smith had a temper, and he sometimes made inappropriate comments like this about other students. But Tyisha was much more likely to be the target because the teachers and students had presupposed that she was a disruptive student.

My data contain at least a dozen other telling examples, from December through May, of how Tyisha was explicitly identified as disruptive by the teachers and students, who accused her of not listening, of being wrong, and of making comments that led the discussion off-track. These comments collectively show that the teachers and students had begun to identify her differently from the way they did earlier in the year. From September through November, Tyisha was just another student, but by February she had become a disruptive student. As such, the teachers and students often assumed that her comments were incorrect or off-topic. Instead of taking time to explore the reasoning behind her comments - and I must add that there was only sometimes clear reasoning discernible behind them--the teachers and other students quickly dismissed Tyisha and moved back to their own discussion.

Tyisha's descent from good, independent-thinking student to disruptive outcast was accomplished, in part, as the class discussed the curricular issue of collectivism and individualism. I have identified eight segments from classroom discussions (lasting, on average, more than half an hour), from November through February, in which Tyisha herself became an example--an example that was discussed as analogous to the text and as analogous to the 
curricular issue on the table. In almost all these cases, the curricular issue involved collectivism and individualism. Tyisha became the favored example when a text included an outcast, someone who acted for his or her own good without considering the good of the society. As the students learned about this curricular issue through these discussions, Tyisha's identity as an outcast became more and more heavily presupposed. Tyisha's identity also got presupposed and reinforced in other classroom events, but I argue that these eight classroom discussions have a particular force because of the extended focus on her as a topic and because of the power that such examples can have (cf. Wortham 1994, 2001b).

\section{A Beast in the Woods}

All of these eight cases--which I argue played an important role in Tyisha's identity development--included a specific kind of speech event. Curriculum becomes a resource for identity development particularly well through a kind of speech event that I call "participant examples" (Wortham 1994, 2001a). Participant examples include, as a character in the example, at least one teacher or student who is participating in the classroom discussion. Such examples double the roles played by those teachers or students because they become characters in the example, as well as participants in the classroom discussion. This doubling of roles makes participant examples rich sites for socially salient interactional positioning. Discussion of participants' hypothetical identities within the example can communicate things about the actual participants, as a sort of double entendre.

Furthermore, the content represented by a participant example and the interactional patterns enacted through that example can sometimes run parallel (Wortham 1994, 1997). That is, in discussing certain events as the content of an example, teachers and students sometimes 
enact analogous events in their classroom interaction. Examples involving such a parallel between representation and enactment are particularly likely to contribute to both social identification and academic learning (Wortham 2001a). This section analyzes one such enacted example that involved Tyisha, to trace how this type of classroom discussion can draw metasigns of identity from the curriculum and help create social identities for students.

This class occurred in late January, once Tyisha's shift from good to disruptive student was well under way. For this class, the students had read selections from Aristotle's Politics, in which he argued that "the state is by nature clearly prior to the individual since the whole is of necessity prior to the part." Aristotle also said that "he who is unable to live in society, or who has no need because he is sufficient for himself, must be beast or god." Aristotle argued for a more collectivist position than we adopt in the contemporary United States. As the teachers tried to help the students understand his position, they focused on the character of a "beast," a person who refuses to make the sacrifices necessary to live as part of society. Mrs. Bailey summarized their discussion of a "beast" in the following excerpt.

1 Mrs. B: OK, so a man who lives outside of society we can

2 understand has this beast quality to him because he's going

3 to do what

$4 \quad$ Female: ${ }^{\circ}$ he wants to do ${ }^{\circ}$

5 Mrs. B: He wants to do when he wants to do it as he wants to

6 do it, with no checks, and no chance to lea:rn what is just or

7 unjust, what is fair or right, to take into account anything

8 beyond what he: wants to $\underline{\text { do. }}$

In the classroom discussion, Mrs. Bailey and some students started to distinguish between such a 
"beast" and a human being. They explored Aristotle's claim that one who does not live in society is not fully human by discussing what humans have that animals do not. They came up with a tentative answer: Humans have goals, while animals do not. Tyisha objected to this definition, in the following passage:

1 Tyisha: Mrs. Bailey? I- I have to disagre:e.

$2 \quad$ [class laughter]

3 Mrs. B: Can I- can I finish this before you disagree,

$4 \quad$ OK. The idea that he's putting out here is that

5 they- they have goals, and that they can in

6 discussion decide the best way to accomplish their

$7 \quad$ goal. Now, Tyisha what's your disagreement?

8 Tyisha: becau(hh)- because if a- like- if my- $\underline{\mathrm{OK}}$,

9 if my cat want to- um you know to get to the top of

10 something, you know, he might sit there and be

11 [three unintelligible syllables] and he'll sit there and

12 try everyday. and then finally he will do it, that was

13 the goal to try and get up there. He had a goal.

14 Mrs. B: OK (1.0) he's got a [goal but

15 Female: [was his goal really

16 necessary? [laughter from the class]

17 Mrs. B: let's- let's- let's take what- (3.0) let's take

18 what your cat's doing that every day he sees that-

19 counter that he wants to get on, and every day when 
20 he passes that counter he tries to get up there. That's

21 a goal. OK[

22 Female: [yeah.

23 Mrs. B: How is that different than your goal, the goal

24 that you might have had last night when you had

25 this reading, or [some chattering]

26 Tyisha: I don't know.

Tyisha offered a reasonable argument here: The teacher and other students claimed that "having goals" distinguishes humans from beasts, but Tyisha pointed out at lines 8-13 that her cat had goals, too. Mrs. Bailey accepted Tyisha's objection at line 14 and at lines $17 \mathrm{ff}$. She granted that Tyisha's cat had goals, and she went on to distinguish between the types of goals Aristotle claimed were uniquely human and the types of goals that beasts also have.

Thus, Tyisha's argument forced the teacher to formulate her interpretation of Aristotle more precisely, and the whole class benefited as they went on to explore the distinction between uniquely human and more widely shared types of goals. Despite her academic contribution here, however, there are already indications that the other students identified Tyisha as a deficient student. At line 2, the students laughed after Tyisha's first utterance. They did so because Tyisha's description of her own action--“to disagree"--fit well with the identity they were presupposing for her as a student who regularly interrupted the class with off-topic opinions. It is only with reference to this presupposed identity that Tyisha's use of "disagree" in line 1 became a sign of identity that the other students found funny. At lines 15-16, another student tried to defeat Tyisha's argument with an apparently weak counterargument. The other students' laughter after this comment seemed to presuppose that because of Tyisha's identity as a disruptive and 
suspect student, Tyisha's argument could be easily defeated (although, as I show later, there is another possible interpretation of the laughter at lines 8 and 16).

Mrs. Bailey, however, recognized the strength of Tyisha's argument, and she did not condone the other students' laughter. She used Tyisha's example of the cat to pursue the academic issue on the table: How are humans different from beasts if beasts have goals apparently just like we do? To continue the discussion, Mrs. Bailey also adopted and developed Tyisha's example, at lines 17-21. As she did so, it became a participant example. Both Tyisha and her cat became characters in the example, and the class explored how Tyisha-the-human's goals might be different from her cat's.

In the next segment, the teachers and students continued to discuss Tyisha's example, to understand how humans are different from beasts:

37 Female: Humans can do more things than cats can do,

$38 \quad$ like they can build

39 Tyisha: No that's not- just a goal. My goal is to win

40 in Nintendo and

41 [laughter by a few girls in the class]

42 Female: that's your goal?

43 Tyisha: it's a go:al, so

44 Mrs. B: OK, maybe winning at Nintendo is like your

45 cat's goal of getting on top of the-

46 Tyisha: right

47 Mrs. B: the- the counter. but aren't- don't we have

48 more [long= 
49 Female: [better

50 Mrs. B: = ranged goals than your cat getting on

51 top of the counter or you winning Nintendo?

52 Tyisha: But I'm just saying they're goals, you said

53 animals can't have goals or something, so I just told

54 ya I disagree.

55 Mrs. B: OK, but can we- can we qualify that then.

56 Tyisha: Yeah.

57 Mrs. B: Can we qualify that and say that man (2.0)

58 doesn't just have immediate goals, but also has-

$59 \quad$ long-range goals.

60 Mr. S: Umm, consider your cat. [Tyisha giggles a bit]

61 your cat gets sleepy. What does your cat do?

72 Mr. S: What goal did you have in mind this morning,

73 even when you went to sleep?

74 Tyisha: [laughing] I didn't h(h)ave o(h)ne.

75 Mr. S: Sure you did. Didn't you- didn't you have the

76 goal you had to wake up at a certain time, get

77 dressed in a- by a certain time, get to a place

78 Tyisha: Yeah that's true.

79 Mr. S: So you had goals even before you s[tarted

80 Tyisha: [but not in 
81 the summertime. I just got up, see, just like

82 Mr. S: $\underline{\text { Ah, }}$ and in summertime when you got up

83 because you had to come to school, what was your

84 goal, or was it to sleep until three in the afternoon?

85 or to get up and play with your friends?

86 Tyisha: The same goal my cat had, to go to sleep

87 and get up and eat.

88 Mrs. B: Ahhh, isn't that interes[ting? [increase in pitch,

89 "mocking" effect]

$90 \quad$ Mr. S: $\quad[$ ahhhh

While Mrs. Bailey and the other students tried to distinguish between humans' and beasts' goals in this segment, Tyisha continued to resist the distinction. At lines 39-40, she argued that her goals--like winning at Nintendo--were similar to her cat's. Mrs. Bailey accepted her argument at lines 44-45, granting that humans have some goals equivalent to beasts'. But the teacher went on to argue that humans also have "more long-range goals" that beasts do not have. At lines 52-54, Tyisha then reiterated her point that the teacher and other students should have been more specific in their claim that "goals" distinguish humans from beasts, and at line 56 she apparently accepted the teacher's intention to distinguish between uniquely human and more beastlike goals.

At line 60, Mr. Smith began to elaborate on Tyisha's example, to pursue the distinction between uniquely human and other goals. At lines 74 and 78, he got Tyisha to contribute information about the content of the example, which he used to argue that Tyisha has uniquely human goals. But at lines 80-81 and lines 86-87, Tyisha reverted to her old argument: She had 
some goals that were qualitatively similar to her cat's, and therefore the teachers' attempt to distinguish humans from beasts (on the basis of goals) could not work. Mrs. Bailey had originally granted that Tyisha's argument pointed out a weakness in the teachers' explication of Aristotle (at line 14), and she did so again at line 44. But after granting Tyisha's claim, she made a reasonable counterargument to it at lines 57-59. Nonetheless, Tyisha continued to make her old argument, that humans like her have beastlike goals, too.

Tyisha's persistence makes clear that there have been two possible "interactional texts" (Silverstein 1992) or "frames" (Bateson 1972; Goffman 1974) for understanding the interaction in play since Tyisha's initial comment at line 1. Each of these frames represents a different set of presupposable social identities for teachers and students. First, Tyisha may have been making an argument, one that contributes to the academic substance of the discussion. In this case, the teachers and students would be on the same side, collaboratively and earnestly participating in an academic discussion. Second, Tyisha may have been using her example as an opportunity to make jokes, by referring to aspects of everyday life that students would not normally be able to discuss in the classroom. The laughter at lines 8 and 16 may reflect Tyisha's skillful manipulation of the academic genre of an "example" to introduce topics not normally discussed in a classroom. In this case, Tyisha would be a "clown," making other students laugh, and she might gain some status by successfully bending the teachers' rules about what could legitimately be discussed. This second frame for the interaction presupposes an opposition between teachers and students, with teachers as disciplinarians and students as restively subject to the teachers' rules.

In the first segment and the beginning of the second, Mrs. Bailey worked hard to “entextualize” (Silverstein 1992; Silverstein and Urban 1996) or frame Tyisha’s example as a 
contribution to academic substance, and she initially succeeded. Tyisha did have a good academic point, and Mrs. Bailey helped her draw it out. But the "joking" frame remains potentially relevant throughout the second segment. A few students laughed at line 41 , probably because the topic of playing Nintendo is not one normally discussed or admitted to in school-yet Tyisha managed to slip it into her example. After Mrs. Bailey accepted Tyisha's argument at line 55 and went on to pursue the distinction between uniquely human and instrumental goals, Tyisha herself laughed at lines 60 and 74 . She may have been trying to turn the example into a joke at this point because she had lost control of it. She was no longer both making an argument and introducing normally taboo topics. The teachers took control of her example, making it part of an academic argument, and Mr. Smith was now controlling the content that Tyisha contributed to the example.

From the teachers' point of view, they were simply returning to normal classroom business. Tyisha made both an academic argument and a joke with the same example, and after she made a substantive point and had her fun, they took control of the example to pursue the curricular topic on the table. Tyisha, however, did not cooperate. She reverted to the same old argument about beasts having goals. From the teachers' point of view--framing the classroom interaction as an academic discussion--this old argument was now an inappropriate distraction. When Tyisha's claim was both a new, substantive argument and a joke, they tolerated the joke for the sake of the argument. But Tyisha's old point no longer contributed to their discussion of the curricular topic. Thus, the teachers became frustrated. I suspect that other students pick up on their frustration, because no one laughed at Tyisha's descriptions of her indolence at lines 80-81 and 86-87. At this point, however, a third potential frame for the interaction--and a metasign of Tyisha's identity--also came into play. At line 88, Mrs. Bailey reacted to Tyisha in a way that 
presupposed neither that she was a student making an argument nor that she was a student making a joke. Mrs. Bailey's mocking tone of voice suggests that she was making fun of Tyisha.

Tyisha's strategy--to resist the distinction between uniquely human and beastlike goals and perhaps to joke with the other students by introducing taboo topics--led her to emphasize her own indolence and beastlike tendencies. Doing so gave the teachers and other students an opportunity to position Tyisha as a morally questionable person, an opportunity they took advantage of.

91 Mrs. B: same goals as her (1.0) [cat=

92 Female: [cat had

93 Mrs. B: = had. Wow.

94 Female: So you are like an animal.

95 Mrs. B: So you are like an animal.

96 Tyisha: I'm not saying, I just don't have

97 somewheres to be at.

98 Mrs. B: OK, but that's not- don't confuse the issue.

99 one point at a time, Tyisha. you throw out 17

100 things and then- nobody can even begin to address

101 any of these things.

102 Male: tss [hissing laughter]

At line 94, a female student made explicit the teachers' interactional move, here calling Tyisha an animal, and Mrs. Bailey echoed her comment. This was likely not part of the argument that the teachers and students had been developing to understand Aristotle. Nor was it part of Tyisha's joking around by introducing normally taboo topics. It is a third frame for the 
interaction, in the which teachers and students singled out Tyisha and laughed at her instead of with her. The students' laughter at line 2, at the beginning of this discussion, was laughter at Tyisha, and by line 102, the students were laughing at her again. This third frame for the interaction presupposes different social identities: The teachers and all the students except Tyisha are on one side, both participating in an academic discussion and using that discussion to tease Tyisha; Tyisha is on the other side, as someone who disrupts the others' academic discussion and as the object of their teasing.

At line 96, Tyisha, recognizing the interactional implications of describing her own indolence, backed off. She had gotten away with joking and arguing at the same time, but now she saw that she had taken it too far--she was outdone in her joking by Mrs. Bailey, who managed to stay within the frame of discussing the example while teasing Tyisha at the same time. Once Tyisha broke off the example at line 96, Mrs. Bailey switched from teasing Tyisha to disciplining her. She explicitly characterized Tyisha as a disruptive student, in line with the presupposed identity that had been developing for a couple of months. By speaking explicitly in her role as an authority figure, Mrs. Bailey formally singled out Tyisha and excluded her as a disruptive outcast.

The class then continued to discuss Aristotle's idea of a "beast" and how someone living without society is not fully human. Mrs. Bailey returned to Tyisha's example in the following segment:

151 Female: A beast- a beast is someone who roams around

152 earth.

153 Mrs. B: A beast is someone who what.

154 Female: roams around the earth. I mean [overlapping 
155 chatter]

156 Mrs. B: You were seeing the connection with Ty-

157 Tyisha's behavior in the summer with being a beast.

158 What's the connection?

159 Tyisha: I'm not a beast, and my cat is not a [beast.

160 Female: [you

161 are a beast.

162 [students laugh]

163 Mr. S: By your definition, you're telling us- by your

164 definition, you're telling us because you have no

165 society, to which you belong in summer by the

166 definition of Aristotle, and your own words, you=

167 Tyisha: [but-

168 Mr. S: $=$ [become a beast in summer $[=$

169 Tyisha: [because-

170 Mr. S: = like your pet.

171 Tyisha: That definition is not the real definition

172 that's in the dictionaries.

173 [students shouting and laughing, overlapping with

174 Mr. S and Mrs. B]

175 Mrs. B: OK, uh, kay, important point. and this- we

176 keep on having a problem with you Tyisha, and this

177 has been ta:lked about and ta:lked about. People 
178 cannot communicate in this kind of conversation

179 unless they agree on using certain terms, a certain

180 way, agree on definitions.

181 Tyisha: But I [

182 Mrs. B: [and if you don't want to agree on the

183 definition, then- I think you remove yourself from

184 the conversation for a while and see where it goes.

185 because we- we are using Aristotle's definitions

186 here, and Natasha was right and that's- (1.0) the

187 issue that we constantly have with you is that you

188 want to come up with a different definition. And

189 that's not what we're about. We're trying to have a

190 discussion based on definitions we've agreed on or

191 come from the piece.

At line 156, Mrs. Bailey returned to Tyisha's example, hoping to explore how humans sometimes act like beasts and have beastlike goals. Tyisha, however, took it as a return to teasing, and she objected. Then the other students joined in, as if it was teasing.

Mr. Smith's comments at lines 163-170 could support either an "academic discussion" (the first) frame or a "teasing Tyisha" (the third) frame for the interaction. His tone was matter-of-fact, and he might have been using the example to continue to interpret Aristotle. But the content of his comment, in which he claimed that Tyisha had "no society" like a beast, might have continued the teasing. The students' laughter and comments at line 173 presuppose this third frame. 
Another clue that teasing--and, as I will show, something more serious about Tyisha's identity as an outcast--was still in play comes from the personal pronoun opposition between "you" and "us" at lines 163 and 175ff. (cf. Wortham 1996). By this point in the conversation, the teachers and students consistently presupposed that Tyisha was not a member of their group. (Earlier, at lines 47 and 57, Mrs. Bailey's "we" might have included Tyisha, but the laughter at Tyisha and their discussion of her as "you," as opposed to "us," later in the discussion show that this was no longer the case. Tyisha also became a "her," excluded from the conversation in the third person, at line 91.) At lines 175ff, Mrs. Bailey explicitly identified Tyisha as a disruptive student who did not participate cooperatively in the communal activity of the class discussion: "We're trying to have a discussion" and "we keep on having a problem with you." For students to have the opportunity to voice their opinions in class, everyone must follow the rules of the group. But Tyisha did not follow these rules, and thus she removed herself from the classroom community.

Within the example, Tyisha argued and the teachers accepted that she was essentially like her cat. Neither Tyisha nor her cat pursued uniquely human goals, and they were therefore removed from human society as Aristotle conceived it. In the classroom itself, a parallel organization emerged. Because Tyisha did not obey the rules of the classroom "society," she was excluded. The teachers and other students agreed on certain rules, and by following them, they belonged to society and acted in uniquely human ways--at least as defined by Aristotle, since he considered rational deliberation in society an essential characteristic of a human being. But Tyisha refused to follow the rules, and thus she was an outcast from the society, a "beast in the woods."

Note how the participant example allowed Tyisha to enact the curriculum. Like her self 
within the example, who acted like an animal and did not participate in society, and like the beast that Aristotle described in the text, Tyisha was excluded from the classroom society. Metasigns of identity from the curriculum, like Aristotle's concept of a beast, were used to position Tyisha herself as an outcast and to reinforce her identity as a disruptive student. Without the curricular theme of society and outcasts from society--which also recurred in several classroom discussions similar to this one on other days--Tyisha's identity might not have developed as it did. Over many examples like this, Tyisha's identity both solidified and became intertwined with the curricular theme of societies and individuals. Her social identity as an outcast from classroom society was made possible, in part, by metasigns of identity that were drawn from the curriculum--like Aristotle's "beast in the woods."

\section{CONCLUSIONS}

Participant examples like the one analyzed here helped the teachers and students draw metasigns of identity from the curriculum and use them to construct Tyisha's social identity as a disruptive outcast. They thus created a complex interdependence between identity development and the curriculum. I am not claiming simply that types of curriculum correlate with types of social identity--like the sometimes-plausible but simplistic claim that skilled science students become "nerds," for example. Details of the curriculum get used to help construct social identities for students and teachers in more subtle and context-specific ways. Tyisha's emerging identity as an outcast and the parallel curricular theme of individuals who refuse to sacrifice for the group illustrate this more subtle interconnection between social identity and academic subject matter.

The concept of social identity has been justifiably central to many accounts of inequality, social reproduction, alienation, and resistance that occur in and through schools. But such work 
has only recently begun to explore in more detail the ways in which micro- and mesolevel patterns mediate the construction of identity and the effects that social identity can have. I have tried to push this discussion forward in two ways. First, this article has shown how an individual student got assigned (and partly adopted) a context-specific identity in ways that drew on but did not simply reproduce existing sociohistorical and mesolevel patterns. Second, by illustrating how curricular categories can contribute to identity development in subtle and context-specific ways, this article has shown how we must attend to the curriculum itself as a potential resource for categories of identity.

But is Tyisha's experience simply a special case? To some extent, it must be. The months-long parallel between a curricular theme and a particular student's identity does not happen in every classroom. These teachers' admirable emphasis on deep themes, instead of isolated facts and skills, made the extensive parallel possible--and many classrooms do not explore themes as deeply. Nonetheless, social identification and learning the curriculum occur in almost all classroom discourse. I have found that these two types of processes intersect more often than we may expect (Wortham 1994, 2001a). So I would guess that metasigns that are drawn from the curriculum contribute to students' identity development in other classrooms as well.

This interdependence between the curriculum and social identity raises both ethical and pedagogical questions. If teaching often shapes students' identity development, do educators have moral responsibilities to examine the types of people their students are becoming? Tyisha's own case is complicated. In the discussion of Tyisha as a beast, the teachers simply did to her what she was doing to them--combined a joke with an argument. Furthermore, Tyisha herself often embraced her identity as an outcast. Nonetheless, the teachers' public belittling of 
her and their exclusion of her from classroom discussion seem inappropriate. So should educators avoid topics that may contribute to social identification? I argue that it is impossible to do so. Interactional positioning and identity development always go on in classroom discourse, no matter how pedagogically successful. The social sciences and humanities curriculum, in addition to being a set of ideas, also represents desirable and undesirable types of people, and these categories can be used to identify to students and teachers themselves. Instead of trying to avoid topics that may lead to identification, we must pay closer attention to the interdependence of academic learning and social identity development. Then perhaps we can reflect more deeply on the kinds of people our students are becoming. 


\section{APPENDIX}

\section{Transcription Conventions}

- $\quad$ abrupt breaks or stops (if several, stammering)

? rising intonation

. falling intonation

_ $\quad$ (underline) stress

(1.0) silences, timed to the nearest second

[ indicates simultaneous talk by two speakers, with one utterance represented on top of the other and the moment of overlap marked by left brackets

$=\quad$ interruption or next utterance following immediately, or continuous talk represented on separate lines because of the need to represent overlapping comments on an intervening line

[...] transcriber's comment

: $\quad$ elongated vowel

${ }^{\circ} \ldots{ }^{\circ}$ segment quieter than surrounding talk

, pause or breath without marked intonation

(hh) laughter breaking into words while speaking 


\section{REFERENCES}

Adler, Mortimer. 1982. The Paideia Proposal. New York: Macmillan.

Agha, Asif. Forthcoming. Language and Social Relations. New York: Cambridge University Press.

Anderson, Elijah. 1999. Code of the Street. New York: W. W. Norton.

Bakhtin, Mikhail. 1935/1981. Discourse in the novel. Translated by Caryl Emerson and Michael Holquist. Pp. 259-422 in The Dialogic Imagination, by Mikhail Bakhtin. Austin: University of Texas.

Bateson, Gregory. 1972. Steps to an Ecology of Mind. New York: Ballantine.

Bourdieu, Pierre. 1984. Distinction. Translated by R. Nice. Cambridge, MA: Harvard University Press.

Bowles, Samuel, and Herbert Gintis. 1976. Schooling in Capitalist America. New York: Basic Books.

Cole, Michael. 1996. Cultural Psychology. Cambridge, MA: Harvard University Press.

Ferguson, Ann. 2000. Bad Boys. Ann Arbor: University of Michigan Press.

Gergen, Kenneth. 1991. The Saturated Self. New York: Basic Books.

Goffman, Erving. 1963. Stigma. New York: Simon \& Schuster.

---. 1974. Frame Analysis. New York: Harper \& Row.

Holland, Dorothy, and Jean Lave, eds. 2000. History in Person. Santa Fe, NM: School of American Research Press.

Lareau, Annette. 2000. Home Advantage. New York: Rowman \& Littlefield.

---, and Erin Horvat. 1999. "Moments of Social Inclusion and Exclusion: Race, Class, and Cultural Capital in Family-school Relationships.” Sociology of Education, 72:37-53. 
Lee, Stacey J. 1996. Unraveling the Model Minority Stereotype. New York: Teachers College Press.

Lemke, Jay. 2000. “Across the Scales of Time.” Mind, Culture, and Activity 7:273-90.

O’Connor, Carla. 2001. "Making Sense of the Complexity of Social Identity in Relation to Achievement: A Sociological Challenge in the New Millennium." Sociology of Education [Extra Issue]:159-68.

Plank, Stephen. 2000. Finding One's Place. New York: Teachers College Press.

Sacks, Harvey. 1972. "On the Analyzability of Stories by Children.” Pp. 325-45 in Directions in Sociolinguistics, edited by John J. Gumperz and Dell Hymes. New York: Basil Blackwell.

Silverstein, Michael. 1992. "The Indeterminacy of Contextualization: When Is Enough Enough?” Pp. 55-75 in The Contextualization of Language, edited by Alonzo DiLuzio and Peter Auer. Philadelphia: John Benjamins.

Silverstein, Michael, and Greg Urban, eds. 1996. Natural Histories of Discourse. Chicago: University of Chicago Press.

Wortham, Stanton. 1994. Acting Out Participant Examples in the Classroom. Philadelphia: John Benjamins.

---. 1996. “Deictic Mapping.” Journal of Pragmatics 25:331-48.

---. 1997. "Denotationally Cued Interactional Events: A Special Case." Semiotica 114:295-317.

---. 2001a. "Interactionally Situated Cognition." Cognitive Science 25:13-42.

---. 2001b. Narratives in Action. New York: Teachers College Press. 
Stanton Wortham, Ph.D., is an Associate Professor and Chair of the Educational Leadership Division, University of Pennsylvania Graduate School of Education. His research applies techniques from linguistic anthropology to study how interactional and social processes go on under the surface of classroom discussions about subject matter. His recent publications have included Acting Out Participant Examples in the Classroom (John Benjamins, 1994), Narratives in Action (Teachers College Press, 2001), Education in the New Latino Diaspora (Ablex, 2001, coedited with Enrique Murillo and Edmund Hamann), and Linguistic Anthropology of Education (Praeger, 2003, coedited with Betsy Rymes). Address all correspondence to Stanton Wortham, Graduate School of Education, University of Pennsylvania, 3700 Walnut Street, Philadelphia,PA 19104-6216; e-mail: stantonw@gse.upenn.edu. 